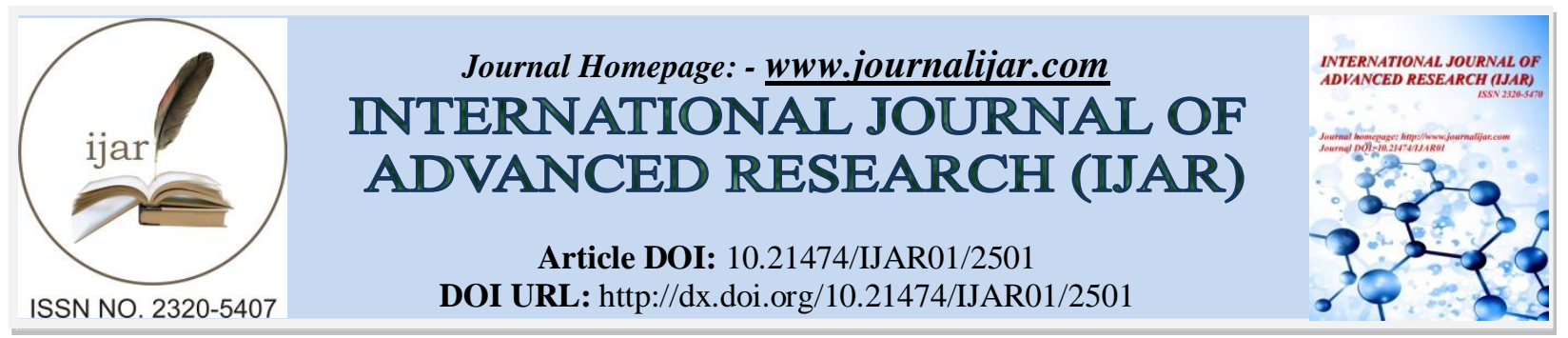

RESEARCH ARTICLE

\title{
EFFECT OF DIFFERENT FERTILIZERS ON OIL PALM (ELAEIS GUINEENSIS) GROWTH AND PERFORMANCE AT NURSERY STAGE IN FELDA SUNGAI TEKAM.
}

\author{
Shampazuraini. S, Siti Aminah. W, Husein. AG and Nuzul Fahmi. AN. \\ Faculty of Plantation and Agrotechnology UiTM Melaka (Campus Jasin), 77300 Merlimau, Melaka Malaysia.
}

\section{Manuscript Info}

Manuscript History

Received: 25 October 2016

Final Accepted: 23 November 2016

Published: December 2016

\section{Abstract}

This paper focused on the use of fertilizer on crop which is gives the best performance on the plant. Type of fertilizer used will give a different effect on crop. The existence of chemical fertilizer such as NPK yellow in the market give an advantage to the farmer in improving crop growth and yield production. As we know that the use of chemical fertilizer became a problem to the farmers, so the fortified fertilizer is necessary as other alternative for expensive chemical fertilizers for small farmers. The cost for fertilizer in plantation also high, especially for large scale crop like oil palm. This experiment was conducted to study the growth and performance of a palm tree (Elaies guineensis) for different type of fertilizers. The experiment was carried out at nursery Pusat Penyelidikan Pertanian Tun Razak (ppptr). The secondary data was collected from the company for 8 months after transplanting of oil palm tree. The data included the plant height, girt size, number of leave and frond length. Data that collected was analysis with Minitab and Microsoft excels application. The result of this study was indicate that there is significant different in the growth and performance of every part of plant. It can be concluded chemical fertilizer give the best result and the fortified organic fertilizer show the good performance same like chemical fertilizer and other fertilizer. This fortified fertilizer also can be use for oil palm seedling.

Copy Right, IJAR, 2016,. All rights reserved.

\section{Introduction:-}

Elaeis guineensis is a tropical forest palm that native to West and Central Africa also one of the cash crops in Malaysia. Grown in plantations it produces 3-8 times more oil from a given area than any other tropical or temperate oil crop. Most modern varieties are from the Tenera (DxP) group, with thin shells and thick mesocarp, which was developed by crossing the wild-type Dura and shell-less Pisifera. The Tenera varieties have high oil content, are easier to process than wild oil palm and are widely cultivated in Asia (Sheil, D. et al. 2009). The native habitat of oil palm is tropical rainforest with $1780-2280 \mathrm{~mm}$ annual rainfall and a temperature range of $24-30^{\circ} \mathrm{C}$ (minimum and maximum) seedlings do not grow below $15^{\circ} \mathrm{C}$ (Sheil, D. et al. 2009).

In most tropical farming communities, the use of inorganic fertilizers to boost yields of oil palm cannot be underestimated as they have been found to increase crop performance as well as the chemical properties of soil structure. Against all these, it has been suggested that organic manures should be used in oil palm production as they are known to increase yield. Inorganic fertilizers are usually not available and are always rather expensive for the low- 
income, small scale farmers. In addition, the fortified fertilizer is advisable to combine the use organic fertilizer with the application of inorganic nutrient sources as needed.

Besides that, there is an alternative economic disposal method being necessary and one potential method is to convert the wastes into compost and put them back on the farm. The recycling of organic waste into fertilizer for crop production can reduce environmental pollution (Sridhar and Adeoye, 2003). This waste has a great potential for reducing fertilizer bill in oil palm plantations and can get more income. This studies to assess the growth and performance of fertilizer for oil palm has carried out in August 2008

\section{Methodology:-}

Location of study:-

The case study was conducted at the Pusat Penyelidikan Pertanian Tun Razak, Jerantut Pahang. The secondary data were collected from the nursery for 8 months after transplanting the oil palm seedling.

\section{Planting materials:-}

The oil palm seed was supplied from Felda Agriculture Service Sdn Bhd. The oil palm varieties was use is Felda DxP Yangambi. The seedling was selected from the pre nursery and transplanting to main nursery.

\section{Treatment application:-}

In this study, four treatments have been used during conducting this study with the recommended rate. The rate of fertilizers that was used for treatment 1 was (NPK Yellow 15/15/6/4), treatment 2 was Fortified Organic (8/8/6/2 + zeolite), treatment 3 was Agroblen SRF (17/8/9/3) and treatment 4 Organic fertilizer (5/5/5/1). The fertilizer was applied on soil surface. Data was collected at 3,6 and 8 weeks after plnating.

\section{Data collection and analysis:-}

Data were recorded based on the plant height, girth size, fronds length and number of leaves.

All the data was analyzed by using minitab 16 software. All the data collected then were analyzed by using Analysis of Variance (ANOVA) and descriptive analysis. The differences between the treatment means data were compared using Tukey's Family Error Rate Test.

\section{Result:-}

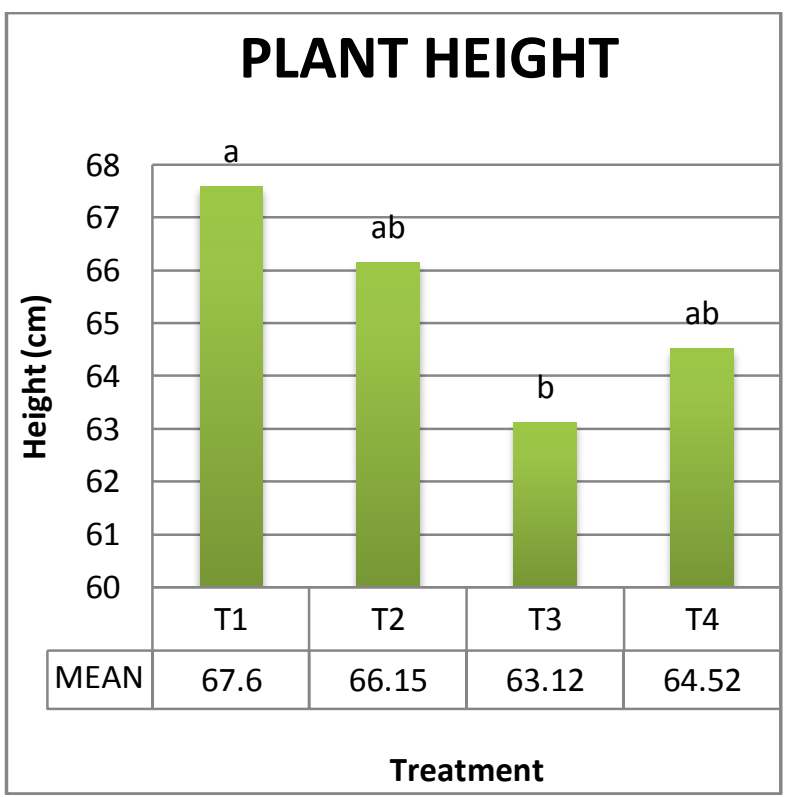

Graph above shows the mean of plant height that applied with NPK fertilizer (T1) show the highest mean $(67.6 \mathrm{~cm})$ of plant height followed with organic fertilizer (T4) and fortified organic fertilizer (T2). The lowest mean $(63.32 \mathrm{~cm})$ of plant height is slow release fertilizer (T3). From the analysis, the mean of T1 and T3 indicated there were significant as show by different letter in graph. According to the ANOVA table, it can be concluded that there are 
significant different in the plant height of the oil palm seedling response to the different type of fertilizer. This is because the $\mathrm{P}$-value in the table is lower than the confident interval applied, 0.05.

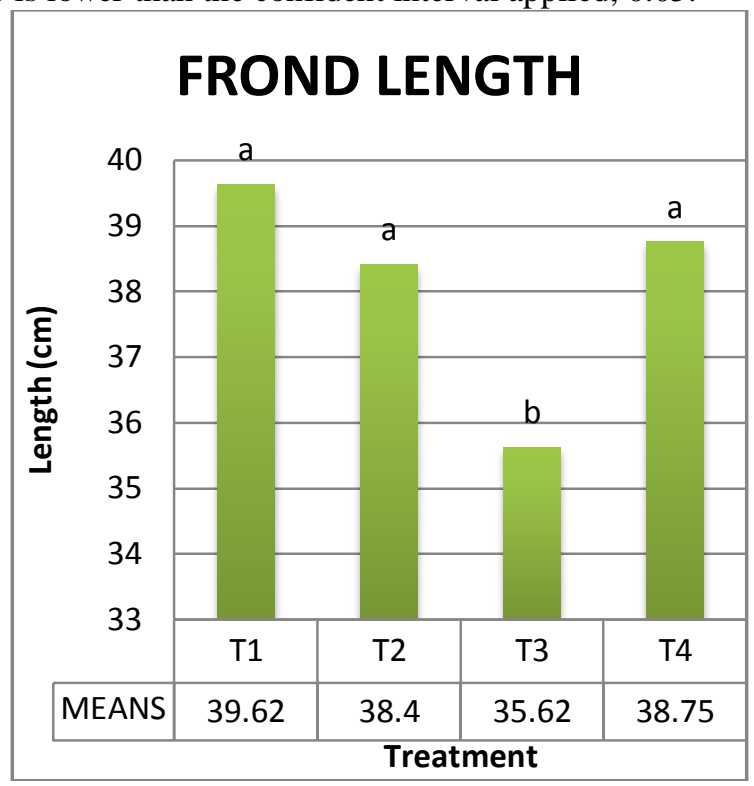

Graph above shows that the plant applied with NPK fertilizer (T1) was the highest mean $(39.62 \mathrm{~cm})$ frond length development followed with organic fertilizer (T4) and fortified organic fertilizer (T2). The lowest mean $(35.62 \mathrm{~cm})$ of the frond length in oil palm development was slow release fertilizer (T3). From turkey family error rates analysis, the mean $\mathrm{T} 3$ show there were significant toward the $\mathrm{T} 1, \mathrm{~T} 2$, and $\mathrm{T} 3$ as showed by different letter in the graph. Regarding to ANOVA table, it can be concluded that there are no significant different in the frond length of the oil palm seedling response to the different type of fertilizer. This is because the P-value in the table is lower than the confident interval applied, 0.05 which is the P-value is 0.009 .

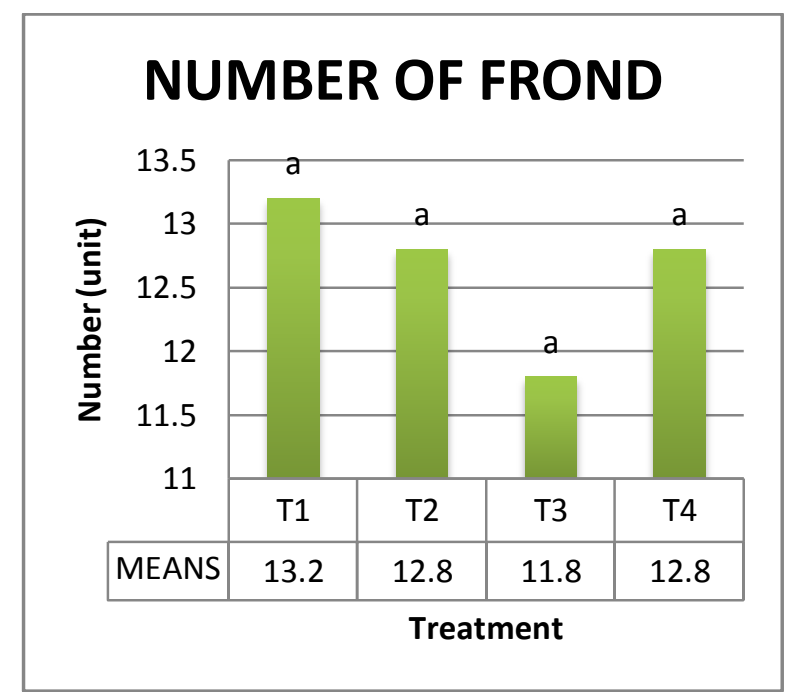

Graph above shows the mean of number of frond with different type of fertilizer for 8 month. From the graft, plant that applied with NPK yellow fertilizer (T1) show the highest mean of number of fronds. The second highest number of frond have a same value of mean which is fortified organic fertilizer (T2) and organic fertilizer (T4) followed with the lowest mean of number of fronds (T3) that applied with slow release fertilizer (SRF). Referring to the ANOVA table, it can be concluded that there are no significant different in the number of frond of the oil palm seedling response to the different type of fertilizer. This is because the P-value in the table is lower than the confident interval applied, 0.05 which is the P-value is 0.301 . 


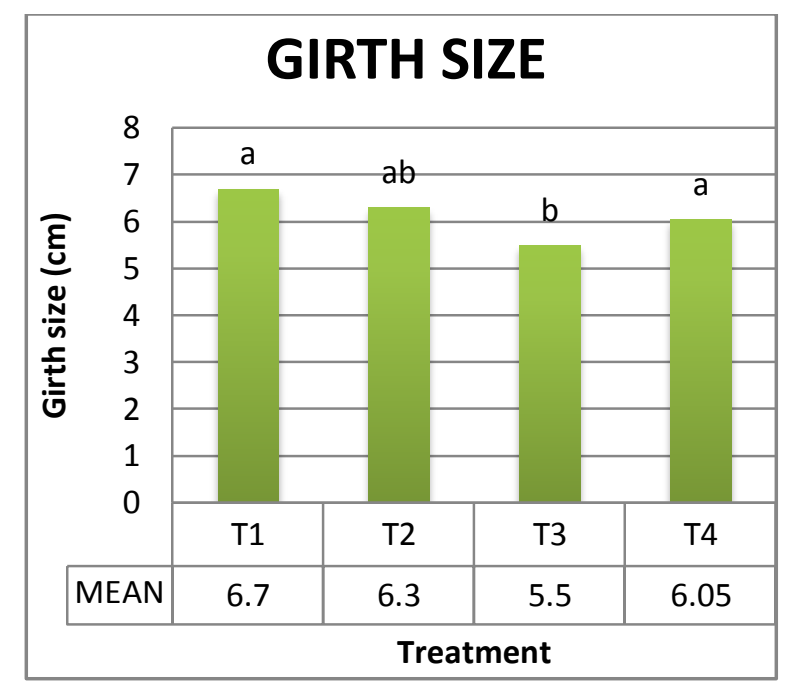

Graph above shows the NPK fertilizer (T1) show the highest mean $(6.7 \mathrm{~cm})$ in girth size compare to other treatment. The second highest mean $(6.3 \mathrm{~cm})$ of girth size was fortified organic fertilizer (T2) and followed by organic fertilizer (T4). The lowest mean $(5.5 \mathrm{~cm})$ of girth size performance is $\mathrm{T} 3$ which is planted with slow release fertilizer. According to the ANOVA table, it can be concluded that there are no significant different in the girth size development of the oil palm seedling response to the different type of fertilizer. This is because the P-value in the table is lower than the confident interval applied, which is 0.969 more than 0.05 .

\section{Discussion:-}

In this study, the usage of different type fertilizer based on organic and inorganic fertilizer on oil palm growth and performance had shown a different effect. At the end of this study, oil palm seedling that has been applied with chemical fertilizer (T1) is highest increments compared to other treatment. All the highest parameter that has been recorded for plant height, frond length, number of frond, and girth size from this study was from the plant that has been fertilized with NPK yellow fertilizer (T1). This is because the NPK fertilizer contains more source of nutrient compared to another treatment in plant uptake. All of this happened cause of NPK in chemical fertilizer is the higher than the other fertilizer. In addition, for the slow release fertilizer (T3) showed the massive different result compared to other plant and it can be conclude that the fertilizer must have ability to release their nutrient rapidly to help the plant grew quickly and healthy.

\section{Conclusion:-}

As conclusion it was found that application 'Fortified Organic Fertilizer ' (8/8/6/2) in the main nursery at 200g rate can give numerous growth and good fertility also comparable with NPK- yellow (chemical fertilizer) and other fertilizer in commercial markets. It is the best alternative to replace Fertilizer NPK yellow, which is used in nursery stage. This is because, the fortified organic fertilizer had only 2 rounds of fertilizer application which is for 1st month rate at $60 \mathrm{~g}$ and 4 th month rate at $140 \mathrm{~g}$ compared to chemical fertilizer that has been applied every month.

\section{Acknowledgement:-}

Alhamdulillah, thanks to Allah S.W.T for giving of HIS blessing, health, patience and motivations in completing report. The authors are thankful to the Management of Faculty of Plantation and Agrotechnology, Universiti Teknologi MARA for their constant support and encouragement. Also thanks to Fundamental Research Grant Scheme (FRGS) 600-RMI/FRGS 5/3 (43/2014) as financial support to complete this research. Also to everyone that helping in completing this experiment directly or indirectly is highly appreciated. 


\section{References:-}

1. AsySyura, M., \& Tsan, F. Y. (2012). The Impact of Organic Fertilizer Application to Oil Palm Production in FELDA Maokil 7: A Case Study. International Plantation Industry Conference \& Exibition, 1-8.

2. Bello, M.M., M.M. Nourouzi, L.C. Abdullah, T.S. Choong, Y.S. Koay and S. Keshani, 2013. POME is treated for removal of color from biologically treated POME in fixed bed column: Applying wavelet neural network (WNN). J. Hazardous Mater., 262: 106-113.

3. Bello, W. B., Ogunjinmi, S. ., \& Ajani, A. (2014). Comparative evaluation of different levels and types of Organo-mineral fertilizers on growth and performance of nursery Palm ( Elaeis guineensis jacq ) Department of soil science and Land management, Federal University of Agriculture; Agriculture and Biology Journal of North America, 5(4), 175-182.

4. Bot, A., \& Benites, J. (2005). The importance of soil organic matter. FAO Soils Bulletin.

5. Effect of Organic and Inorganic Fertilizers and Their Combinations on the Growth and Yield of Maize in the Semi-Deciduous Forest Zone of Ghana a Thesis Submitted To the Department of Crop and Soil Sciences , College of Agriculture and Natural. (2010). Science, 162.

6. Fairhurst, T.H. and Mutert, E. 1999 Introduction to oil palm production. Better Crops International 13: 1-6. FAOSTAT http://faostat.fao.org (18 Sep. 2008).

7. Food and Agriculture Organization of the United Nations, \& International Fertilizer Industry Association.(2000). Fertilizers and their use, 34. 